\title{
PSpice Model for Optimization of battery Charging using Maximum power point Tracker
}

\author{
${ }^{* 1}$ Md. Fahim Ansari, ${ }^{2}$ Anis Afzal,, S.Chatterji, ${ }^{2}$ Atif Iqbal, ${ }^{3}$ N.K Nautiyal and ${ }^{4}$ Padmanabh \\ Thakur \\ 1. NITTTR Chandigarh, \\ 2.AMU Aligarh, , \\ 4 MNNIT Allahabad \\ 3, GEU Dehradun, \\ *Corresponding author.Tel: +919761866637,E-mail: fahim402001@yahoo.co.in
}

\begin{abstract}
Lithium-ion (Li-ion) batteries, pulse width modulator (PWM) control method is implemented to design and build a solar battery charger prototype. Maximum power point tracking (MPPT) is used in the photovoltaic (PV) system to maximise the PV output power, irrespective of the temperature and irradiation conditions. MPPT system, consisting of a buck-type dc-dc converter, which is controlled by a microcontroller unit, is implemented. It is presented a model for the lithiumion battery (Li-Ion) that is suitable for computer simulation. The used model can be easily modified to fit data from different batteries. The simulation results achieved by using Pspice programs and are in good agreement with the experimental results. These results allowed demonstrating the reliability and validity of the proposed MPPT technique. The battery charger prototype was tested and the results obtained allowed to conclude about the conditions of permanent control on the battery charger.
\end{abstract}

Keywords: dc-dc converter, maximum power point tracking, microcontroller, photovoltaic systems, solar battery charger

\section{Introduction}

Photovoltaic sources are used today in many applications such as battery charging [1], light sources [2], water pumping [3], satellite power systems [4], etc. Since PV modules still have relatively low conversion efficiency, the overall system cost can be reduced using high efficiency power trackers which are designed to extract the maximum possible power from the PV module (maximum power point tracking, MPPT) [5]. The main goal of this paper is to study the use of solar power to charge lithium-ion batteries. In the literature, many battery charging techniques are investigated and proposed [6]-[7]. These methods use a variety of battery characteristics like voltage and temperature to achieve a s afe and fast charging process. However, in this paper a simple maximum power point tracking technique, known as Voltage MPPT (VMPPT) [8], is simulated and constructed. The implementation and simulation of the proposed method uses a low-cost, low-power consumption microcontroller, which controls a buck type dc-dc converter and performs all control functions required by the MPPT process and battery charging.

Due to their high energy densities and long life times, Li-Ion batteries are increasingly used in systems such as portable electronics, electric vehicles [9], etc.

\section{Description of system}

The photovoltaic charger system consists of four subsystems, each with its own function. These four subsystems are connected in accordance with the block diagram shown in Figure 1. The first subsystem consists of solar panel of polycrystalline PV module from Solarex. This PV module has a rated power of $12 \mathrm{~W}$ att and is formed by 18 photovoltaic cells connected in series. Second subsystem is charger unit which includes a dc-dc converter controlled by a PWM signal. Dc-dc converter is formed by two switches and an input and output filter [10]. 
Third subsystem (control unit), consists of a programmable interface circuit (PIC) microcontroller, model PIC18F4585, and an integrated circuit (IC), SG3524. PIC microcontroller is a high performance 8-bit reduced instruction set code (RISC) architecture, operates from $2 \mathrm{~V}$ to $5.5 \mathrm{~V}$ belonging to 40 pins family and IC is a 16 pin PWM switching regulator.

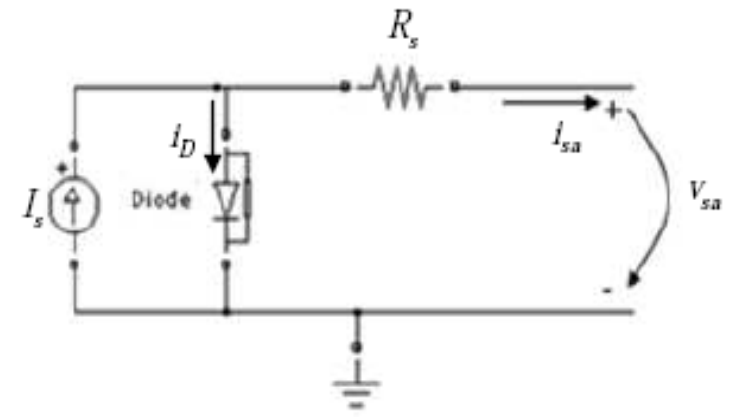

Fig. 1.Equivalent circuit of solar cell

However, when it is connected to an external supply a current $i_{D}$ called diode current will be present. A solar cell is usually represented by an electrical equivalent one-diode model [3] with a series resistance, as shown in Fig.1. The model contains a current source $I_{s}$ one diode and a resistor $R_{s}$. The net current is the difference between the photocurrent $I_{s}$ and the normal diode current $i_{D}$. The diode current is given by equation (1).

$i_{D}=I_{0} \times\left\{e^{\frac{V_{s a}+R_{g}}{m \times V_{T}}}-1\right\}$

Where:

$I_{0}=$ diode current (strongly dependent on temperature);

$V_{s a}=$ voltage imposed across the cell;

$m=$ Ideal factor (ideal: $m=1$; real: $m>1$ );

$V_{T}=$ Thermal potential $=\frac{K \times T}{q}$

$R_{s}=$ Series cell resistance;

Where

$K$ : Boltzmann constant, $K=1.38 \times 10^{-23} \mathrm{~J} / K$;

$\mathrm{T}:$ cell temperature in $K$

$q$ : electric charge of electron, $q=1.6 \times 10^{-19} C$.

hence net current $i_{s a}$ is given by

$i_{s a}=I_{s}-I_{0} \times\left\{e^{\frac{V_{s a}+R_{s}}{m \times V_{T}}}-1\right\}$

\subsection{Charger Circuit}

Fig. 2 gives a general description of the charging unit block. A dc-dc converter consists of a number of storage elements and switches that are connected in a topology such that the periodic switching controls the dynamic transfer of power from the input to the output, in order to produce the desired dc conversion. The two fundamental topologies of dc-dc converters are the buck and the boost converter as described [11]. The purpose of the dc-dc 
converter is to transform a DC voltage from one level to another. This is done by varying the duty cycle, $\partial$. Dc-dc converters have two distinct operating modes; continuous conduction mode $(\mathrm{CCM})$ and discontinuous conduction mode (DCM). The paper takes the advantage of $\mathrm{dc}-\mathrm{dc}$ converter working in CCM.

The low pass filter (LPF) is a simple RC filter where the capacitor is in parallel with the load. The combination of resistance and capacitance gives the time constant of the filter:

$\tau=R X C$

The cut off frequency is given by

$f_{c}=\frac{1}{2 \pi R C}$

\subsection{Electrical Model for Li-ion Battery}

The duration of the battery cycle is the total amount of discharge-charge cycle that a battery relieves before more power cannot be hold. The energy of the battery, expressed in Watt-hour, $W h$, is the product of the capacity and the voltage of the battery, $V$. Fig.2 represents an intuitive and comprehensive electrical battery model.

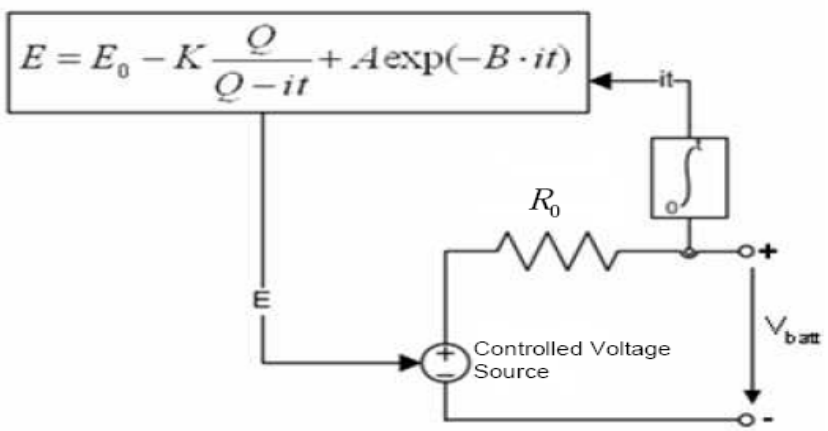

Fig.2 Equivalent circuit models of Li-ion battery

Where,

$E=$ Internal voltage, $\mathrm{V}$;

$E=$ Constant voltage, $\mathrm{V}$;

$K=$ Polarization voltage, $\mathrm{V}$;

$Q=$ Battery capacity, Ah;

$A=$ Exponential Voltage, $\mathrm{V}$;

$B=$ Exponential Capacity, $\mathrm{Ah}^{-1}$

The terminal voltage $V_{\text {batt }}$ is given by equation 5

$V_{\text {batt }}=E-I_{\text {batt }} \times R_{0}$

\section{Simulation results in Pspice}

The use of Pspice is very useful in cases where there is the need to determine the values of voltage and current circulating in the circuit, in order to investigate the range of values of some components, or even just to make changes in topology. With the help of this simulation program it was possible to build a basic circuit of a step-down switching regulator with duty 
cycle ratio control. The circuit is depicted in Fig. 3 and allows the modulation of the dc-dc converter. Specification of the used components may be consulted in as shown below;

\section{Voltage source}

$\mathrm{V}_{0}=\mathrm{V}_{1}=\mathrm{V}_{2}=10 \mathrm{~V}_{\mathrm{dc}}$

\section{Resistances}

$$
\begin{array}{ll}
\mathrm{R}_{1}=4 \mathrm{k} \Omega & \mathrm{R}_{4}=5 \mathrm{k} \Omega \\
\mathrm{R}_{2}=4 \mathrm{k} \Omega & \mathrm{R}_{5}=5 \mathrm{k} \Omega \\
\mathrm{R}_{3}=15 \mathrm{k} \Omega & \mathrm{R}_{\mathrm{PV}}=15 \Omega
\end{array}
$$

\section{DC-DC Converter components}

$\mathrm{C}_{1}=10 \mu \mathrm{F}$

$\mathrm{L}_{1}=300 \mu \mathrm{H}$

$\mathrm{C}_{2}=100 \mu \mathrm{F}$

$\mathrm{Q}_{1}$-MOSFET 2N6660

Diode - D1N5817

\section{IC SG3524 components}

$$
\mathrm{C}_{3}=5 \mathrm{nF}
$$

$\mathrm{C} 4=100 \mathrm{nF}$

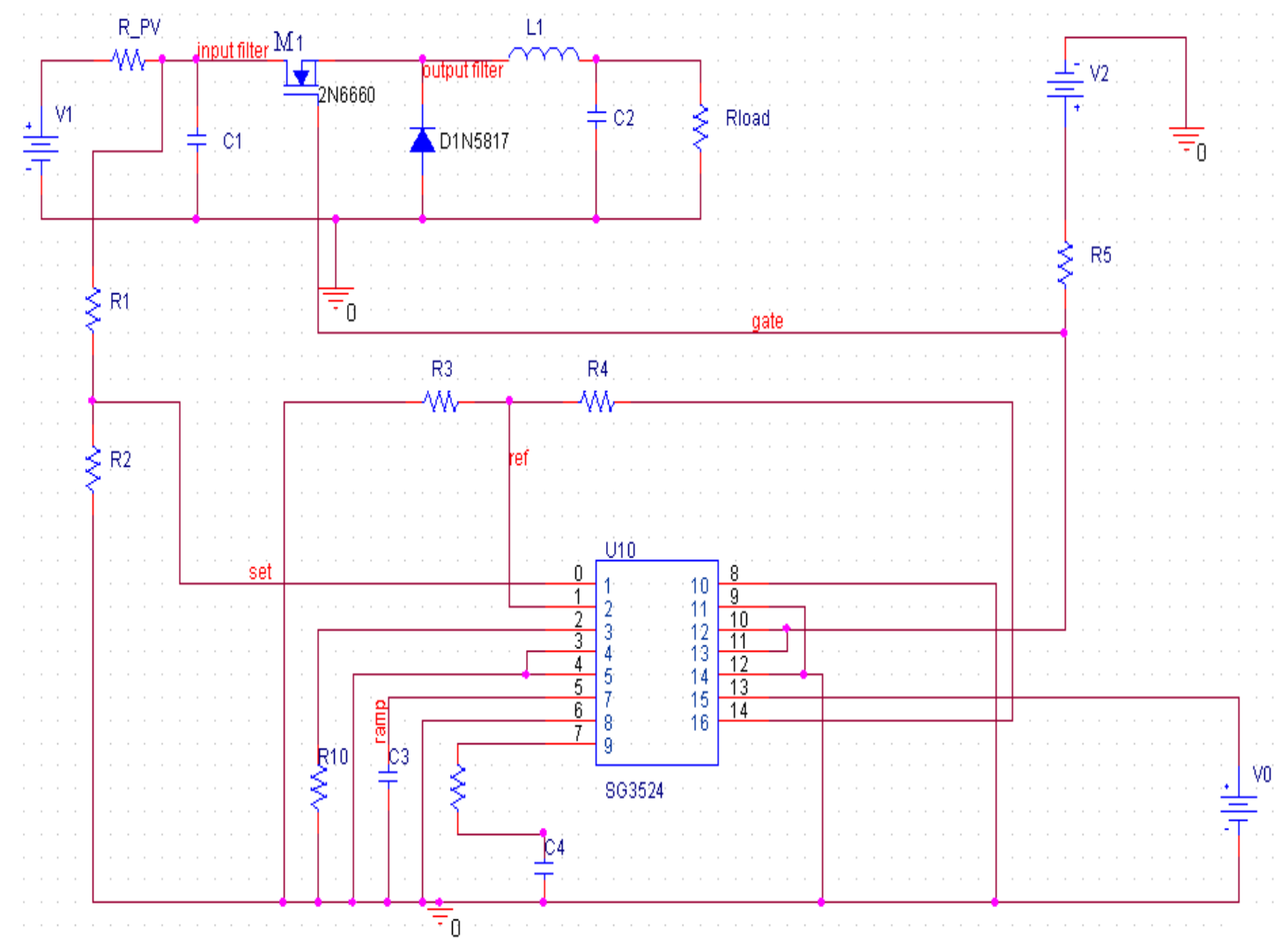

Fig.3-Step-down switching regulator circuit

Two schemes were simulated for both $R_{\text {load }}=20 \Omega$ and $R_{\text {load }}=40 \Omega$. It is assumed that the circuit is working on the MPPT point and that all the results obtained depend of it. The value of $V_{\text {set }}$, output voltage of the solar panel is tending to this operation point which allows predicting that the circuit is being controlled: without knowing the value of the output voltage 
and current the system evolves to the maximum power rate that the PV model allows VMPPT algorithm. There is a permanent control of the system duty cycle ratio control. Another important aspect worth to look at is the ripple value of the $V_{s e t}$ voltage corresponds to the solar panel output voltage. In Fig.4 the maximum ripple obtained is nearly $3 \%$ of the voltage value $\nabla V_{c_{1}}=0.1 \mathrm{~V}=V$, which means that capacitor, $\mathrm{C}_{1}$ is well dimensioned.
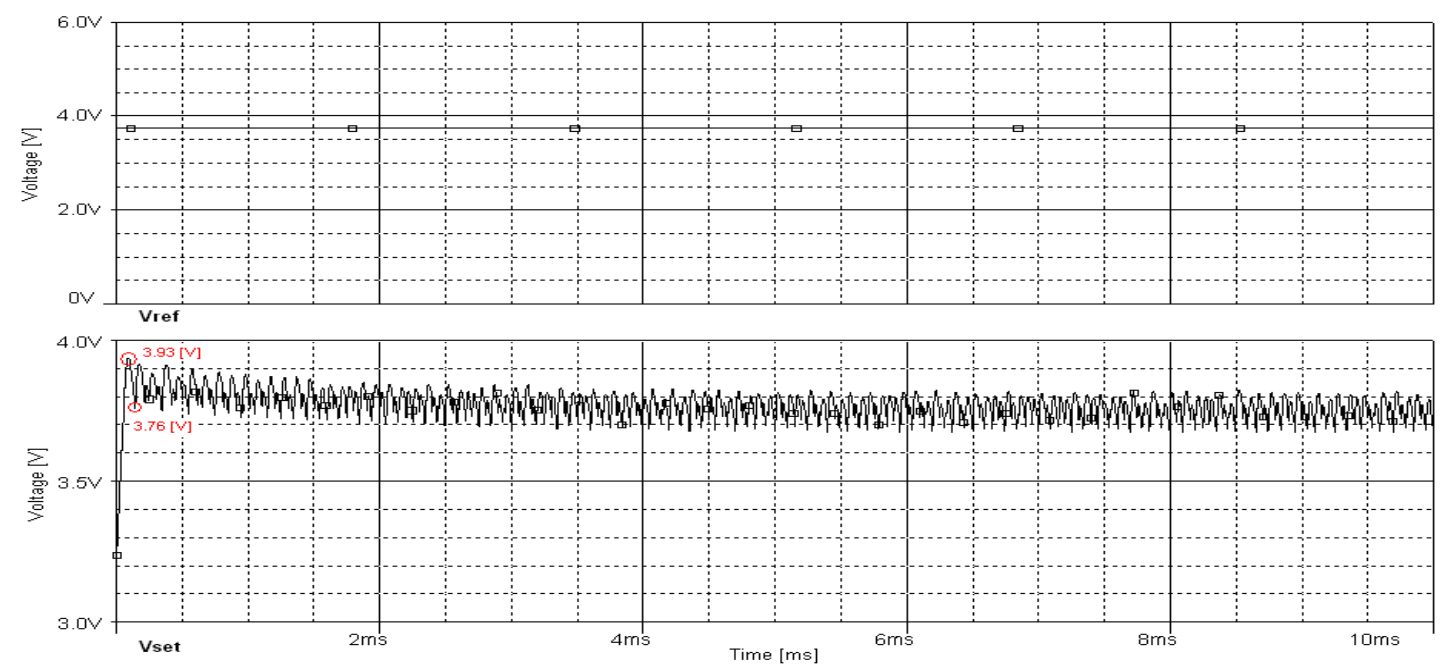

Fig.4variation of $\mathbf{V}_{\text {set }}$ and Vref for $\mathbf{R}_{\text {lozd }}=20 \Omega$

Fig.4 presents the result of the difference between $V_{r e f}$ and $V_{\text {set }}$ The PWM signal gives us the final idea that the system is, in fact, being controlled. Variation of $V_{\text {set }}, V_{\text {ref }}$ and $V_{\text {gate }}$ are given in Fig. 5

Fig.5 presents the voltage and current that is present in the load $\left(R_{\text {load }}=20 \Omega\right)$, this resistive load reflects the ideal conditions for the charging process, taking into account the technical specifications of the chosen battery, presenting very good values for voltage $V_{R \text { load }}=4.1 \mathrm{~V}$ and current $i_{\text {load }}=205 \mathrm{~m} A$. The initial conditions $\left(V_{R \text { load }}=4.8 V\right.$ and $\left.i_{\text {load }}=240 \mathrm{~m} \mathrm{~A}\right)$

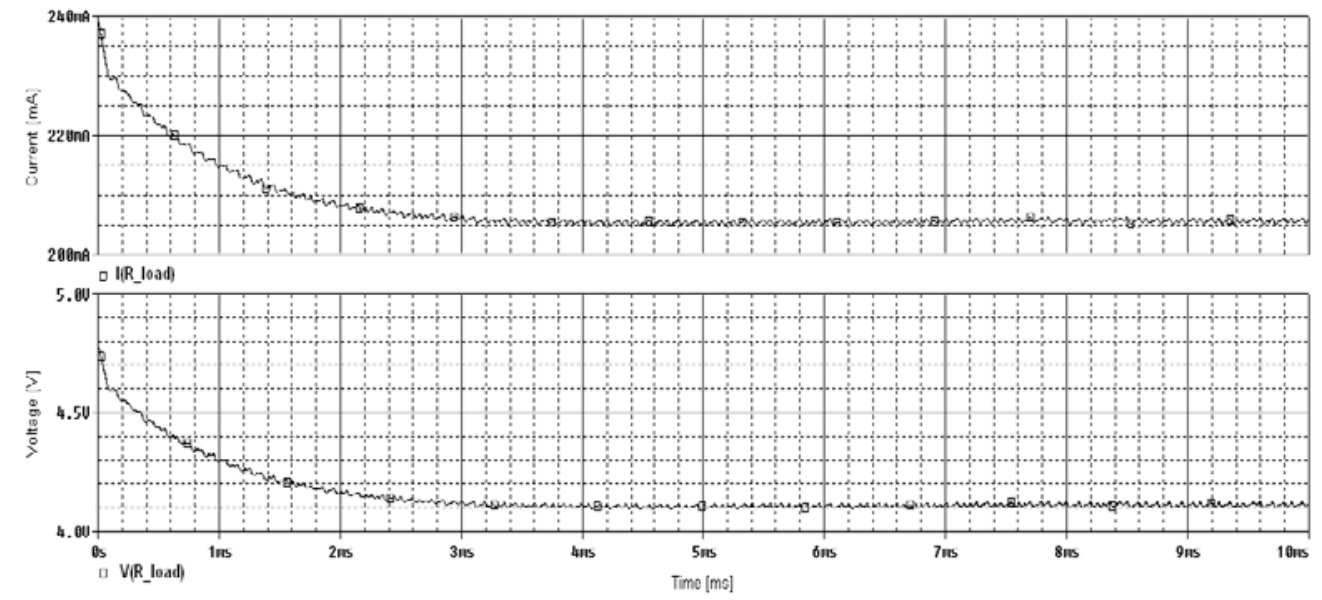

Fig. 5 variation of $I\left(\boldsymbol{R}_{\text {load }}\right)$ and $V\left(\boldsymbol{R}_{\text {load }}\right)$ at $\boldsymbol{R}_{\text {load }}=20 \Omega$

Fig.6 presents current in inductor $L_{1}$ and voltage across diode for $R_{\text {load }}=40 \Omega$.. Current in inductor is always $i_{L_{1}}>0$ the converter is in CCM. When current in inductor decreases, the 
diode is forward biased and hence converter is working correctly. This figure shows that current in the circuit is well dimensioned: current $i_{L_{1}}$ does not go to complete zero which allows the circuit to work in CCM.

Fig.7 presents voltage across the resistance $R_{\text {load }}=40 \Omega$. Although the voltage is too high for the conditions stated in this paper and so the system is no longer controlling the ratio power between the input voltage sources which simulates the solar panel for the resistive load.

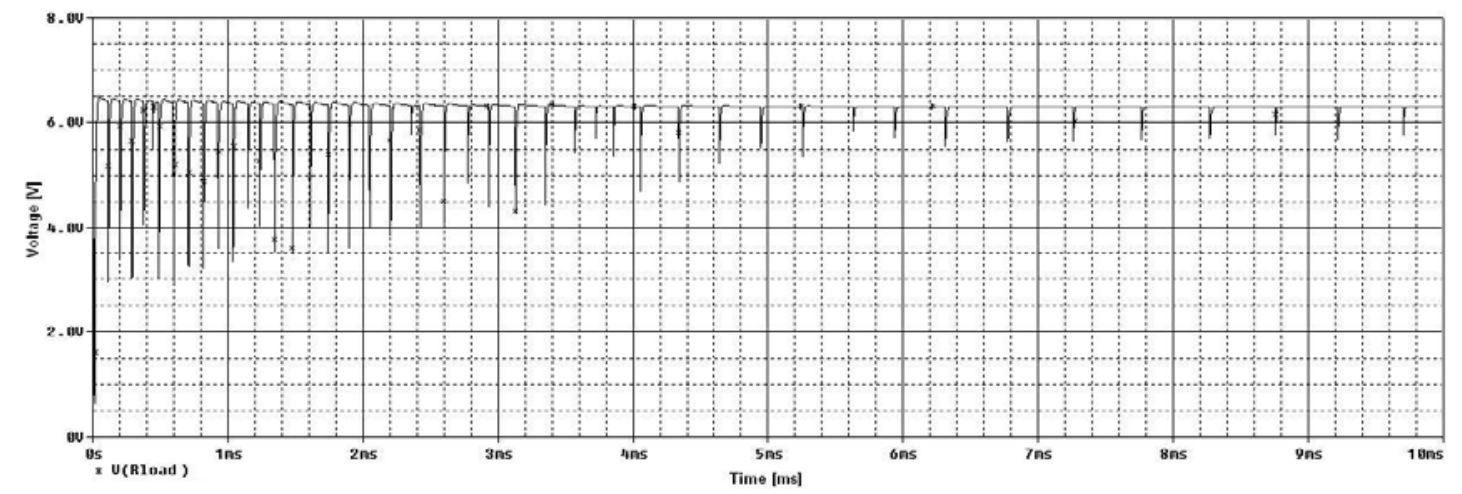

Fig. 7 Voltage across load resistance $\boldsymbol{R}_{\text {load }}=40 \Omega$

Fig. 8 presents the situation where the system is being controlled for $R_{\text {load }}=20 \Omega$ contrasting to Fig. 9 where $R_{\text {load }}=40 \Omega$, the control is practically inexistent. If current $i_{L}$ is lower than $150 \mathrm{~mA}$ the system loses $V_{\text {gate }}$ control and starts deficient control which shows that the current limit for control is achieved.

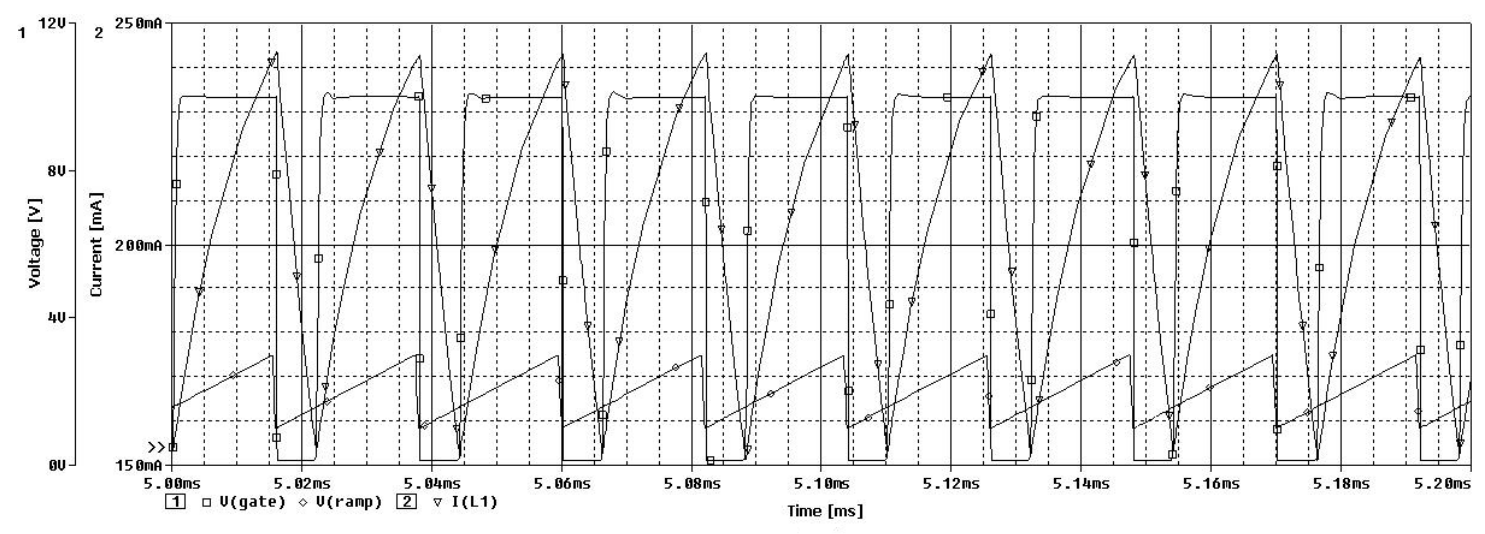

Fig. 8 variations of $V_{\text {gate }}, \boldsymbol{i}_{L}$ and $\boldsymbol{V}_{\text {rampSG3524 }} \boldsymbol{R}_{\text {load }}=20 \Omega$

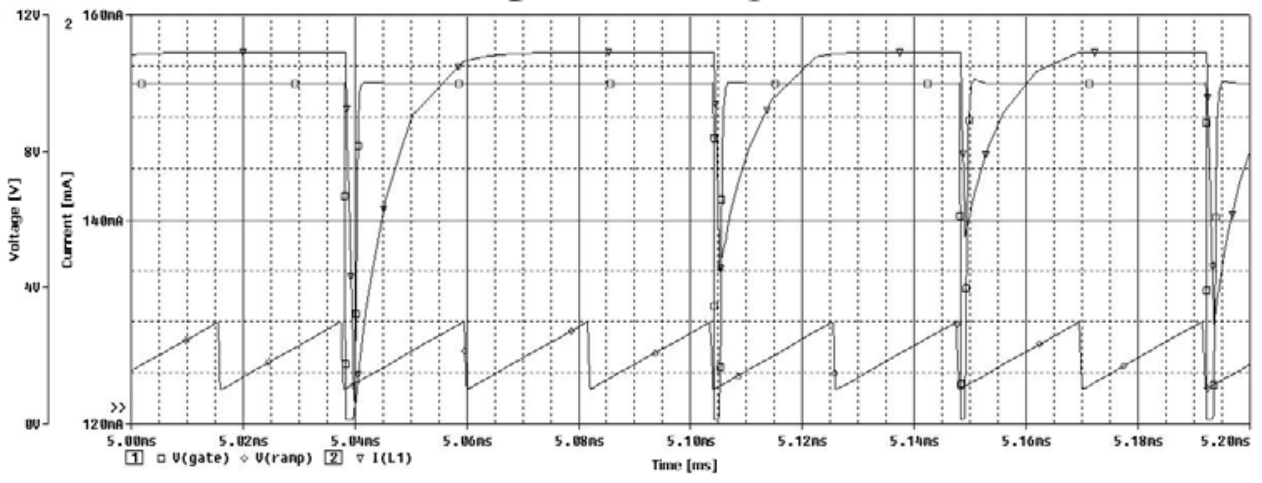

Fig. 9 variations of $V_{\text {gate }}, \boldsymbol{i}_{L}$ and $V_{\text {rampSG3524 }} \boldsymbol{R}_{\text {load }}=40 \Omega$ 
Fig.10 presents the maximum power transfer rate that operating in the maximum power point the solar panel provides, more or less $P_{\max p v} \approx 1.2 \mathrm{~W}$. Therefore, the representation of the solar panel by an ideal voltage source and resistance is reliable for this system.

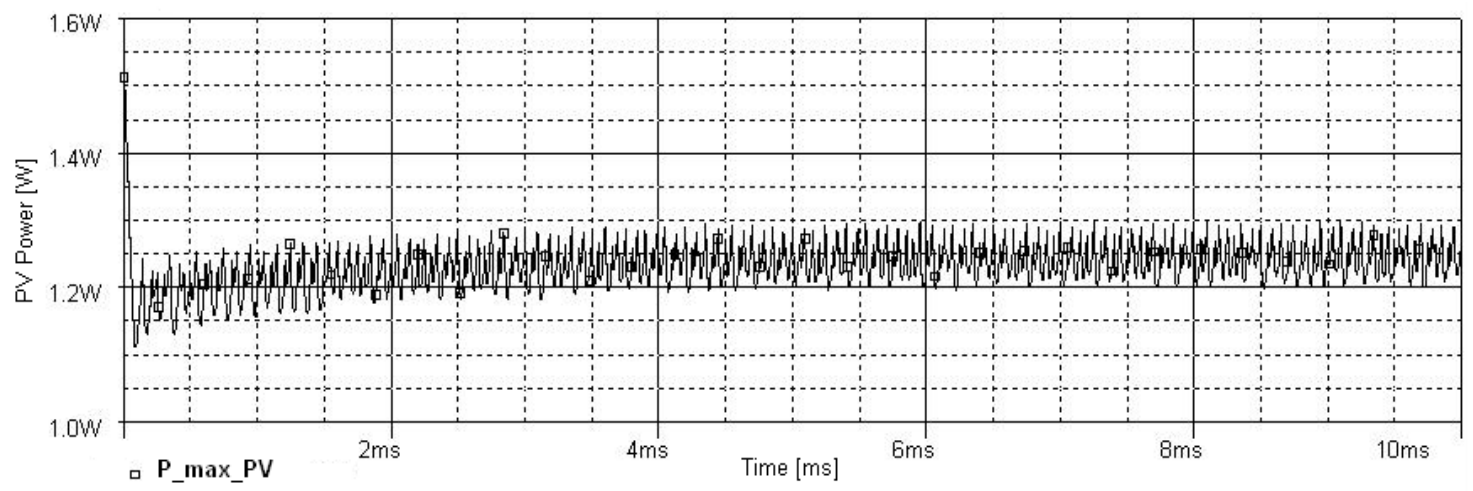

Fig.10 PV Output Power

Fig.11 and Fig.12 presents the power across the $20 \Omega$ and $40 \Omega$ load, respectively. In the individual graphs it is possible to look at the power loss: $R_{\text {load }}=20 \Omega$ the system presents a power loss for $20 \Omega$ load resistance $\approx 1.2-0.85=0.35 \mathrm{~W}$ and power loss for $40 \Omega$ load resistance $\approx 1.2-0.89=0.31 \mathrm{~W}$. With these results it is possible to conclude that the system is not ideal, even referring to a simulation program. Nevertheless, regardless of the load value, the system presents power conservation: the final power value achieved is very similar in both cases even if the system with $R_{\text {load }}=40 \Omega$ loses control.

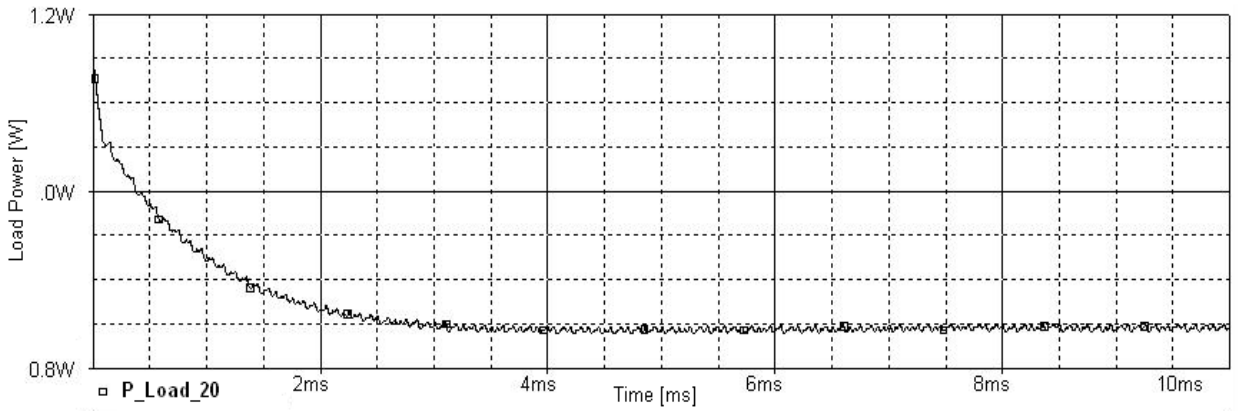

Fig.11 Load Power $\boldsymbol{R}_{\text {load }}=20 \Omega$

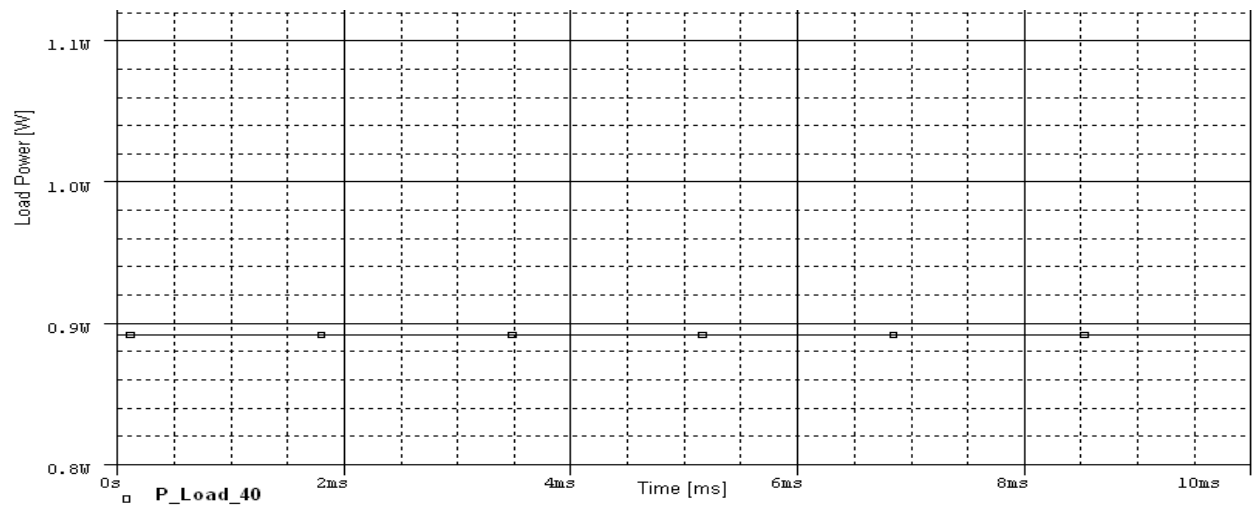

Fig.12 Load Power $\boldsymbol{R}_{\text {load }}=40 \Omega$ 


\section{Conclusions}

The use of Pspice simulation program allows a better understanding of the system behavior when in the presence of variable loads. It can be generally stated that while the system is represented by a load of $R_{\text {load }}=20 \Omega$, it allows a controllable system. The duty cycle ratio control is a constant premise. For this reason the values obtained at the output of the system voltage and current are the ideal ones for an optimum battery charger in this case, optimum values for the type of battery chosen. Although the losses presented in the system, probably due to losses of the transistor switching and internal resistance, the system presents a very good behavior and a faithful representation of what will happen in reality. Since system is very sensitive to load variations. The system starts losing control for load values above $40 \Omega$ presenting a load voltage higher than the one allowed to correctly charging the Li-Ion battery. The maximum voltage value in the load that allows the duty ratio control of this system is close to $5.2 \mathrm{~V}$.

\section{References}

[1] Mohamad A. S. Masoum, Seyed Mahdi Mousavi and Ewald F. Fuchs, "MicroprocessorControlled New Class of Optimal Battery Chargers for Photovoltaic Applications", IEEE Transactions on Energy Conversion, Vol. 19, No.3, Sep. 2004.

[2] Md.Fahim Ansari,S.Chatterji and Atif Iqbal"AUTOMATIC PEAK POWER TRACKER FOR SOLAR PV MODULES USING d SPACE SOFTWARE”. International Journal of Sustainable Energy,Taylor and Francis Vol. 29 No. 3 September2010 pp 151-163,

[3] Md.Fahim Ansari,S.Chatterji and Atif Iqbal "A FUZZY LOGIC CONTROL SCHEME FOR SOLAR PHOTO VOLTAIC SYSTEM FOR MAXIMUM POWER POINT TRACKER" International Journal of Sustainable Energy,Taylor and Francis 29: 4, 245 - 255,December 2010.

[4] K. Tanaka, E. Sakoguchi, Y. Fukuda, A. Takeoka, and H. Tokizaki, "Residential solar powered air conditioner", in Proc. Eur. Power Electronics Conf., Brighton, U.K., Apr. 1993, pp.127-132.

[5] E. Koutroulis and K. Kalitzakis, "Novel battery charging regulation system for photovoltaic applications", IEE Proc.-Electr. Power Appl, Vol. 151, No. 2, March 2004.

[6] Lijun Gao, Shengyi Liu, and Roger A. Dougal, "Dynamic Lithium-Ion Battery Model for System Simulation", IEEE Transactions on Components and Packaging Technologies, Vol. 25, No.3, Sep. 2002, pp1521-3331.

[7] Wei Zhang, Dale Skelton and Robert Martinez, Modelling and Analysis of an Off-line Battery Charger for single Cell Lithium Batteries”, IEEE, Sep. 2004.

[8] Mohamad A. S. Masoum, Hooman Dehbonei and Ewald F. Fuchs, "Theoretical and Experimental Analyses of Photovoltaic Systems With Voltage and Current Based Maximum Power Point Tracking", IEEE Transactions on Energy Conversion, Vol. 17, No.4, Dec. 2002.

[9] http://www.mathworks.com/toolbox/physmod/powersys/ref/battery.html, Apr. 2008.

[10]Min Chen and Gabriel A. Rincón-Mora, "Accurate Electrical Battery Model Capable of Predicting Runtime and I-V Performance", IEEE Transactions on E nergy Conversion, Vol. 21, No.2, June 2006.

[11] José Fernandes Alves da Silva, Sistemas de Energia em Telecomunicações: Texto de Apoio, Set 05-06, Instituto Superior Técnico, Área Cientifica de Energia, Portugal, May. 2006. 